\title{
Current Situation and Countermeasures for Education of Ancient Chinese Learning in Higher Vocational Colleges from the Perspective of Internet Plus \\ Qiu-fei REN ${ }^{1, a,{ }^{*}}$ \\ ${ }^{1}$ Ideology and Politics Teaching Department, Dalian Vocational \& Technical College, Dalian, 116035, China \\ renquifei@126.com
}

Keywords: Education of Ancient Chinese Learning, Internet plus, Higher Vocational Colleges.

\begin{abstract}
In the era of "Internet plus", the media matrix is formed gradually, which for higher vocational colleges to carry out the education of ancient Chinese learning has brought opportunities and challenges. Based on the investigation of five vocational colleges in Dalian, this paper used the methods of questionnaire survey, field investigation and case interview, analyzed five major problems. With the "Internet plus" era, this paper gives five different counter measures and suggestions respectively to higher vocational colleges.
\end{abstract}

\section{Introduction}

Generally, the education of ancient Chinese learning includes at least three parts of traditional Chinese culture, traditional art and folk culture. The education of ancient Chinese learning plays an important role in the cultivation of students' ideal and belief, humanistic accomplishment, professional ethics, innovation ability and so on[1]. "Internet plus" era not only ushers in a new round of technological revolution, but also influences the social management mode, mode of thinking and lifestyle changes, especially driven by the emerging media types, the media came into being, which for higher vocational colleges to carry out the education of ancient Chinese learning has brought opportunities and challenges.

Therefore, we urgently need to study the characteristics of the education of ancient Chinese learning in "Internet plus" era, to summarize the problems in education, to find a new starting point to carry out the educations of ancient Chinese learning in higher vocational colleges, to explore effective educational contents and methods, to innovate the education of ancient Chinese learning practice, and to enhance the charm and appeal of the education of ancient Chinese learning.

\section{Current Situation (Taking Dalian Region as an Example)}

We have visited five higher vocational colleges in Dalian, randomly selected 100 teachers and students as the object, and investigated the colleges to carry out the situation of the education of ancient Chinese learning.

\section{The Education of Ancient Chinese Learning in Colleges}

Research shows that more than $90 \%$ of the teachers and students in higher vocational colleges to implement the positive attitude of the education of ancient Chinese learning (refer with: Fig. 1). 


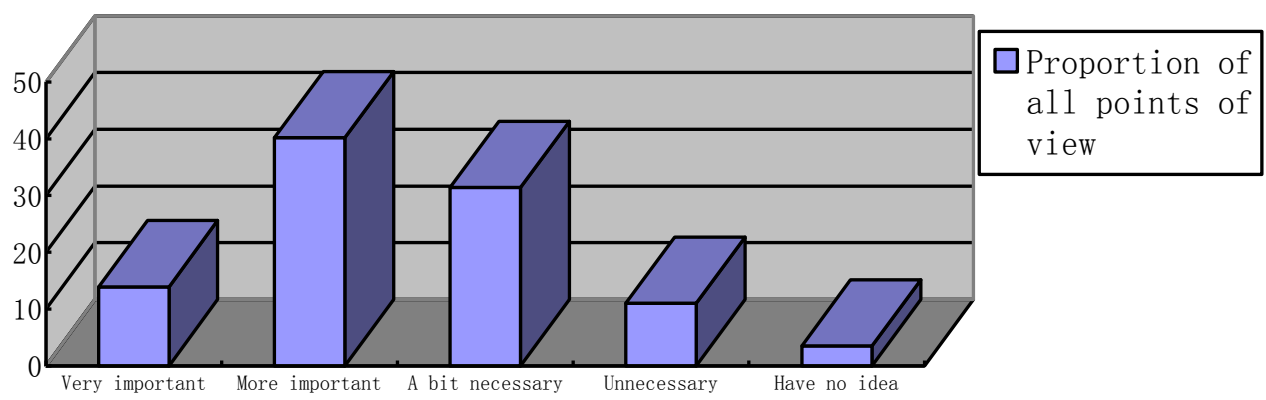

Figure1. The attitudes of teachers and students in higher vocational colleges' to the education of ancient Chinese learning

Ancient Chinese learning in the campus covers the Chinese culture into the classroom, the Chinese culture into the campus culture, the Chinese culture into the activities of students, Chinese culture into practice and so on. The best implementation is the covering Chinese culture education into the classroom. It is shown that more than $80 \%$ of specialties have taken "Chinese writing" as a basic course in the talent training scheme, $23 \%$ of specialties have required the course of Chinese ancient civilization to be established, such as calligraphy, Chinese painting, tea art and folk arts. All the visited colleges have established Chinese ancient civilization lessons. However, $12 \%$ of students have taken such courses.

The deep pursuit of traditional sinology education accumulates the campus culture and sets university culture temperament [2]. The campus culture in these five colleges has reflected the Chinese ancient civilization indeed.

Above all, there is a few works in the area of Chinese culture into student activities and practices. Some schools have established the ancient Chinese learning associations such as the Chinese culture research society, the Chinese chess club, the calligraphy and the ink painting club and so on. Also, some colleges have carried out the reading of classical Chinese classics, the knowledge competition and other practical activities.

\section{Chinese Ancient Civilization of Teachers and Students}

The education of ancient Chinese learning is the education to convey Chinese excellent ideology and cultivate Chinese national consciousness and national spirit. However, the conservative and backward factors in Chinese ancient civilization make itself declined in the exchange of Chinese culture and foreign culture in modern times, and quieted the stage of history on occasion. In the age of knowledge economy, Chinese ancient civilization's valueand a function solving the new problems was rediscovered [3]. Hence the education of ancient Chinese learning has become the hot spot gradually.

A survey on "How many classical poems can you recite?" The answer is not satisfactory (refer with: Fig. 2).

\section{Problems and Causes}

The problems as follows: 1 . The education content is relatively simple and not closely related to the students' professional; 2 . The qualified teaching stuff are unbalanced and led to reduced interesting in ancient Chinese learning;3. Most colleges do not have a system of courses; 4 . The emphasis on education is insufficient, and the propaganda idea is not enough; 5. There is a big difference between teaching results.

The corresponding causes for the above problems include: 1. Historical reasons results in misunderstanding of Chinese ancient civilization; 2. Some colleges do not 
attach importance of ancient Chinese learning since higher vocational technology education is in the direction of employment; 3 . Some vocational college students think that ancient Chinese learning has been out of date.

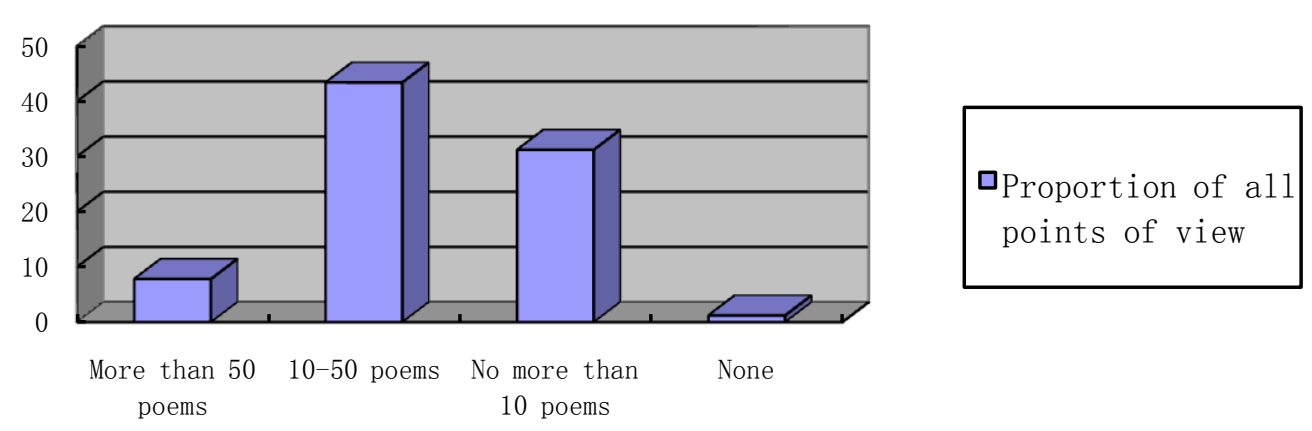

Figure2. How many classical poems can you recite?

\section{Countermeasures and Suggestions}

Based on the findings of the investigation and analysis, tentative countermeasures and suggestions are presented as follows:

\section{To Further Support the Development of Educations}

Education departments at all levels should regard the education of ancient Chinese learning as an important part of quality education. Higher vocational colleges should fully recognize the role of Chinese culture in shaping the growth of students, and conscientiously carry out the education.

\section{To Improve the Curriculum and Made Teaching Plan}

Higher vocational colleges should improve the curriculum and teaching plan of ancient Chinese learning. Colleges should combine the ancient Chinese learningcurriculum with the basic courses and professional courses, and organize teaching in different grades.

\section{To Strengthen the Construction of Teaching Staff and Platform Construction}

The government relies on colleges and universities who carry on the training to teachers of the education ancient Chinese learning. Educationaldepartments establish all-roundeducational centersof ancient Chinese learning.Also, higher vocational colleges set up national education bases. The higher vocational colleges should organize regular education activitiesaround the center or platform.

\section{To Adopt a Flexible and Diverse Teaching Methods}

The interest is the first motive force in the ancient Chinese learning. Therefore, the stimulation ofstudent's learning interest becomes the first requirement.To achieve this aim, teachers should try many different teaching approaches, and emphasize an interactive type and the research in the teaching methods.

And the teaching methods should be flexible.Teachers can adopt the multimedia methods, such as story-telling, discussion and being in real situation to raise students' interest of learning and achieve better teaching results.

\section{To Adhere to the Long Term of Education}

The education of Chinese ancient civilization will be a long-term task, and be difficult to achieve the desired effect. In general, the higher vocational education lays stress on 
specialties and practicalities [4]; teachers also train students' pertinent post skills. Hence, for the education of ancient Chinese learning in higher vocational colleges, the biggest obstacle is that the environment is in a state of practical and utilitarian [5]. Higher vocational colleges should institute scientific middle and long run layouts. Also, everything goes according to schedule, although some have questioned to this.

To guarantee continuity of such process, colleges can carry out by making reading-aloud cards, putting the credit system into practice, and setting up studying file bags about ancient Chinese learning.

\section{Conclusions}

Various of methods are applied, such as documentation, comparison, questionnaires, observations and interviews, and ensure scientificity of process and results. With the "Internet plus" era, we concluded five major categories of problems, analyzed the reasons for the problems from four aspects of society, colleges, students, teachers, given five countermeasures and suggestions to strengthen the education of ancient Chinese learning in higher vocational colleges.

We investigated the educational forms, educational contents, educational methods and effects of ancientChinese learning in five higher vocational colleges in Dalian. From the research situation, most of higher vocational colleges have carried out different types of the education of ancient Chinese learning. In the form, it includes the Chinese culture into the classroom, the Chinese culture into the campus culture, the Chinese culture into the activities of students, Chinese culture into practice and so on.Among them, putting Chinese culture into the classroom is the best aspect. The educational content of ancient Chinese learning includes traditional sinology, traditional arts and folk culture.Teaching organization mode is mainly classroom teaching, although the classroom teaching mode benefits their education of the humanities, quality education and impartment of knowledge and conforms to the traditional continental teaching system, the question lies in the cultivation of the students' practical abilities. So in the survey, a lot of students have expressed that ancient Chinese civilization is very far away from their lives.

In summary, there are five major problems in higher vocational colleges to carry out the education of ancient Chinese learning as follows: teaching content are not systematic; the qualified teaching stuff are unbalanced; most of schools do not have a system of courses; the emphasis on education is insufficient; there is a big difference between the effect of teaching.

The reasons are followings below: 1.Historical reasons results in misunderstanding of ancient Chinese learning; 2.Higher vocational technology education is in the direction of employment, so some schools do not attach importance of ancient Chinese learning; 3. Some students in vocational college think that Chinese ancient civilization is out of date.

With the "Internet plus" era, this study gives five different counter measures and suggestions respectively to higher vocational colleges. Based on the research findings, effective approaches have been proposed to solve problems include: 1.To further support the development of educations; 2.To improve the curriculum and teaching plan; 3 . To strengthen the construction of teaching staff and platform construction; 4 . To adopt a flexible and diverse teaching methods; 5. To adhere to the long term education of Chinese ancient civilization. 


\section{References}

[1] WANG Xi, SU Shang-feng, CAO Ting-ting, The Value of Education in Chinese Ancient Civilization, Journal of Beijing Normal University(Social Sciences). 4 (2014) 30-37.

[2] BI Tian-zhang, On the Popularity of Education Studies of Chinese Ancient Civilization - The New Approval for Chinese Ideology Culture Tradition, Journal of Henan Institute of Education (Social Sciences).4 (2006) 46-50.

[3] Zhang Tie-dao, Zhu Chuan-shi, A Mission for Chinese Cultural Education, Chinese Journal of Educational Science. 3 (2014) 229-250.

[4] LIU Gui-ping, Theory of traditional Chinese education promoted the role of higher vocational students' professional quality, Joual of Mudajiagivesiy. 4 (2014) 160-162.

[5] Information on, http://news.Eastday.com/eastday/node127047/node127048/node127092/node127111/ node127113/userobject1ai2173236.html. 